\title{
HUBUNGAN SIKAP KERJA DENGAN KELUHAN NYERI PUNGGUNG BAWAH PADA PENENUN DI KABUPATEN BATUBARA
}

\author{
Sonia Mahfira ${ }^{1}$, Tri Niswati Utami ${ }^{2}$ \\ Fakultas Kesehatan Masyarakat, Universitas Islam Negeri Sumatera Utara Medan ${ }^{1,2}$ \\ soniamahfira@gmail.com ${ }^{1}$,mkesoetami@yahoo.co.id ${ }^{2}$
}

\begin{abstract}
Low Back Pain (LBP) occurs in people who work in a sitting position, bending, lifting and pulling. Low back complaints are pain, aches that occur in the lower back area and can radiate to the legs, especially the back. Low back pain is also a type of disease that many craftsmen complain about, due to repetitive movements, prolonged sitting, and non-ergonomic working positions. The purpose of this study was to analyze the relationship between work attitude and complaints low back pain weavers in Batubara Regency. Purpose of this study was to analyze the relationship between attitude and complaints of low back pain weavers in Batubara Regency. This type of research uses quantitative methods descriptive analytical with a cross sectional research design approach with a total sample of 70 peoples. Variables studied were work attitudes and complaints of low back pain. Data analysis using Chi Square Test. Collecting data using a questionnaire and measuring work attitudes using the REBA method. Based on the results of the Chi Square test, the $\rho$-value of 0.015 is smaller than 0.5, so it can be concluded that there is a relationship between work attitude and complaints of low back pain in weaver workers in Batubara Regency. Recommended that workers before starting work should do light exercise for stretching such as moving the neck, arms, legs, and hitting the back several times and pay attention to working time according to working hours where a maximum of 6-8 hours per day is worked.
\end{abstract}

Keywords $\quad$ : Bend Down, Low Back Pain, Reba, Weaving Work, Work Attitude

\begin{abstract}
ABSTRAK
Keluhan nyeri punggung bawah terjadi pada orang yang bekerja dalam posisi duduk, membungkuk, mengangkat dan menarik. Keluhan nyeri punggung bawah adalah nyeri yang terjadi pada daerah punggung bawah dan dapat menjalar ke kaki terutama punggung. Keluhan nyeri punggung bawah juga merupakan jenis penyakit yang banyak dikeluhkan penenun, akibat gerakan berulang, duduk lama, dan posisi kerja yang tidak ergonomis. Tujuan dari penelitian ini adalah untuk menganalisis hubungan antara sikap kerja dengan keluhan nyeri punggung bawah pada penenun di Kabupaten Batubara. Tujuan penelitian ini untuk mengetahui hubungan sikap dengan keluhan nyeri punggung bawah pada penenun di Kabupaten Batubara. Jenis penelitian ini menggunakan metode kuantitatif deskriptif analitik dengan pendekatan desain penelitian cross sectional dengan jumlah sampel 70 orang. Variabel yang diteliti adalah sikap kerja dan keluhan nyeri punggung bawah. Analisis data menggunakan Uji Chi Square. Pengumpulan data menggunakan kuesioner dan pengukuran sikap kerja menggunakan metode REBA. Berdasarkan hasil uji Chi Square didapatkan nilai sebesar $\rho$-value 0,015 lebih kecil dari 0,5, sehingga dapat disimpulkan bahwa ada hubungan antara sikap kerja dengan keluhan nyeri punggung bawah pada pekerja penenun di Kabupaten Batubara. Disarankan agar pekerja sebelum mulai bekerja melakukan olahraga ringan untuk peregangan seperti menggerakkan leher, lengan, kaki, dan memukul punggung beberapa kali serta memperhatikan waktu kerja sesuai jam kerja dimana maksimal 6-8 jam per hari bekerja.
\end{abstract}

Kata Kunci : Membungkuk, Nyeri Punggung Bawah, Reba, Pekerjaan Penenun, Sikap Kerja

PENDAHULUAN

Nyeri punggung bawah atau Low back pain (LBP) merupakan rasa nyeri, ngilu, pegal yang terjadi di daerah punggung bagian bawah. Pekerjaan yang mengharuskan pekerja menggunakan posisi duduk, posisi duduk beresiko tinggi terjadi pada low back pain. Salah satu pekerjaan 
yang menggunakan posisi duduk adalah penjahit (Damayanti, 2021).

World Health Organization (WHO) menyatakan bahwa kondisi musculoskeletal adalah penyebab tertinggi kedua di dunia, dengan nyeri punggung bawah menjadi penyebab utama kecacatan secara global. Studi Global Burden of Disease (GBD) memberikan bukti dampak kondisi musculoskeletal, beban disabilitas yang signifikan yang terkait dengan kondisi ini. Sementara itu, prevalensi kondisi muskuloskeletal bervariasi yaitu berdasarkan usia dan diagnosis, antara $20 \%-33 \%$ orang di dunia mengalami sakit karena kondisi muskuloskeletal (World Health Organization, 2018).

Kejadian nyeri punggung bawah atau Low Back Pain di Amerika Serikat merupakan 1 dari 10 penyakit terbesar dan menduduki peringkat ke lima dalam daftar penyebab seseorang yang berkunjung ke dokter (Minghelli, 2017). Menurut data Direktorat Jenderal Pelayanan Kesehatan Kementerian Kesehatan Republik Indonesia (Kemkes RI), prevalensi LBP di Indonesia sebesar $18 \%$ (Kemenkes RI, 2018).

Low Back Pain (LBP) di Indonesia merupakan masalah kesehatan yang nyata. LBP merupakan penyakit nomor dua pada manusia setelah influenza. Data untuk jumlah penderita LBP di Indonesia belum diketahui secara pasti, namun diperkirakan penderita LBP di Indonesia bervariasi antara $7,6 \%$ sampai $37 \%$ dari jumlah penduduk yang ada di Indonesia (Tho, 2018).

Penelitian yang dilakukan oleh PERDOSSI (Persatuan Dokter Saraf Seluruh Indonesia) yang dilakukan pada 14 kota di Indonesia pada tahun 2002 menemukan adanya $18,1 \%$ pengidap nyeri punggung bawah. Nyeri ini pada akhirnya akan berkaitan dengan kondisi depresi, sehingga dapat mengganggu kualitas hidup dan menurunkan level aktivitas pada pekerja (Noli, Sumampouw, \& Ratag, 2021).
Pekerja yang harus bekerja dengan postur tubuh tidak ergonomi akan mengalami nyeri akibat otot tubuh tertekan dalam rentang waktu yang cukup panjang. Sikap kerja membungkuk selama bekerja merupakan salah satu dari faktor risiko low back pain (LBP), sebab sikap kerja membungkuk dapat memperbesar risiko low back pain (LBP) sebesar 2,68 kali dibandingkan dengan pekerja dengan sikap badan tegak (Agung, 2017).

Kelompok pekerja penenun sering mengalami keadaan postur yang kaku dan beban otot yang statis akibat tugas yang berulang-ulang dengan kecepatan produksi yang tinggi (Damayanti, 2021). Dalam melakukan pekerjaan, seseorang atau sekelompok pekerja berisiko mendapat kecelakaan dan penyakit akibat kerja. Penyakit akibat kerja merupakan penyakit yang timbul karena hubungan kerja atau yang disebabkan oleh pekerjaan. Aktivitas sehari-hari yang menuntut banyak gerak ke depan maupun membungkuk, bekerja pada posisi duduk dengan jangka waktu yang lama dimungkinkan menyebabkan nyeri pada bagian anggota badan, punggung, lengan, bagian persendian, dan juga jaringan otot lainnya (Damayanti, 2021).

Penelitian tentang hubungan postur kerja dengan keluhan Low Back Pain (LBP) pada pengrajin batik menunjukkan ada hubungan yang signifikan antara postur kerja dengan keluhan Low Back Pain (LBP) berdasarkan hasil uji chi square dengan nilai $\mathrm{p}$-value 0,007 ( $\mathrm{p}$-value $<0,05$ ) (LBP) (Harahap, Marisdayana, Rara, \& Al Hudri, 2019).

Berdasarkan hasil survei awal yang dilakukan saat pekerja tenun bekerja dengan posisi duduk yang membungkuk dalam jangka waktu yang lama. Sehingga tidak ergonomis dalam melakukan pekerjaan yang menyebabkan keluhan Low Back Pain pada Penenun Tradisional di Kabupaten Batubara. Observasi awal pada penenun terdapat 8 dari 10 orang penenun diantaranya pernah mengalami keluhan nyeri punggung bawah atau Low Back Pain (LBP). 
Adapun tujuan dalam penelitian ini adalah untuk mengetahui hubungan sikap kerja dengan keluhan Low Back Pain (LBP) pada penenun tradisional di Kabupaten Batu Bara. Dengan hipotesa ada hubungan antara sikap kerja dengan keluhan nyeri punggung bawah (low back pain) pada penenun tradisional di Kabupaten Batubara.

\section{METODE}

Penelitian ini menggunakan jenis penelitian Kuantitatif dengan metode Deskriptif Analitik dengan pendekatan desain penelitian cross sectional. Penelitian ini dilakukan di Kabupaten Batubara pada tanggal 08 Agustus 2021. Populasi pada penelitian ini adalah pekerja penenun yang bekerja dan sampel sebanyak 70 orang dengan teknik pengambilan sampel pada penelitian ini menggunakan non probality sampling dengan menggunakan pendekatan purposive sampling. Dengan menentukan kriteria sampel dengan purposive sampling, yaitu hubungan antara sikap kerja dengan keluhan nyeri punggung bawah pada penenun di Kabupaten Batubara.

Pengumpulan data melalui penyebaran kuesioner identitas dan kuesioner tentang nyeri punggung bawah. Sikap kerja diukur dengan pengukuran metode REBA (Rapid Entry Body Assesment). REBA (Rapid Entire Body Assessment) adalah sebuah metode dalam bidang ergonomic yang digunakan secara cepat untuk menilai postur leher, punggung, lengan, pergelangan tangan dan kaki seorang pekerja (Sulaiman \& Sari, 2016).

Sebelum kuesioner diberikan kepada responden, terlebih dahulu dilakukan uji validitas dan reabilitas kuesioner pada 32 orang pekerja penenun ulos di Desa Siopatsosor Kabupaten Samosir Provinsi Sumatera Utara Tahun 2018. Dengan hasil uji chi-square diperoleh $\rho$-value 0,020 karena nilai $\rho$-value $<0,05$ sehingga disimpulkan Ho ditolak yang artinya ada hubungan antara sikap kerja dengan keluhan nyeri punggung bawah.

Analisis data dalam penelitian ini ialah menggunakan uji Chi-Square untuk mengetahui hubungan atau pengaruh dua buah variabel nominal. Hasil akhir akan diperoleh dari Fisher's Exact Test. Fisher's Exact Test adalah uji signifikan statistik yang digunakan dalam analisis tabel kontingensi. Meskipun dalam praktiknya digunakan ketika ukuran sampel kecil, itu berlaku untuk semua ukuran sampel.

\section{HASIL}

Hasil analisis univariat dan bivariat disajikan sebagai berikut :

\section{Analisis Univariat}

Analisis univariat menjelaskan tentang karakteristik responden serta variabel penelitian ditampilkan pada Tabel 1, Tabel 2, dan Tabel 3 dibawah ini:

\section{Tabel 1. Karakteristik Responden}

\begin{tabular}{lll}
\hline Karakteristik & N & $\%$ \\
\hline Usia & & 54,3 \\
$20-40$ & 38 & 45,7 \\
$>40$ & 32 & 100 \\
Jenis Kelamin & & 0 \\
Wanita & 70 & 0 \\
$\quad$ Pria & 0 &
\end{tabular}

Sumber: Data Primer

Berdasarkan tabel diatas ditinjau dari usia, responden yang berusia 20-40 tahun yaitu sebanyak 38 orang $(54,3 \%)$, dari jenis kelamin, semua pekerja ialah wanita sebanyak 70 orang (100\%). 
Tabel 2. Distribusi Frekuensi Keluhan Nyeri Punggung Bawah

\begin{tabular}{lll}
\hline Keluhan Nyeri Punggung Bawah & N & \% \\
\hline Ringan & 21 & $30 \%$ \\
Berat & 49 & $70 \%$ \\
Total & 70 & $100 \%$ \\
\hline
\end{tabular}

Sumber: Data Primer

Berdasarkan tabel diatas diketahui bahwa keluhan nyeri punggung bawah yang dialami pada pekerja penenun di
Kabupaten Batubara berada dalam kategori keluhan berat 49 orang (70\%) dan kategori keluhan ringan sebanyak 21 orang (30\%).

Tabel 3. Distribusi Frekuensi Sikap Kerja

\begin{tabular}{lll}
\hline Sikap Kerja & $\mathbf{N}$ & $\mathbf{\%}$ \\
\hline Sangat Rendah & 0 & 0 \\
Rendah & 0 & 0 \\
Sedang & 18 & $25.7 \%$ \\
Tinggi & 52 & $74.3 \%$ \\
Sangat Tinggi & 0 & 0 \\
Total & 70 & $100 \%$ \\
\hline
\end{tabular}

Sumber: Data Primer

Berdasarkan tabel diatas diketahui bahwa sikap kerja pada penenun di Kabupaten Batubara berada dalam kategori tinggi yaitu sebanyak 52 orang $(74.3 \%)$ dan dalam kategori sedang yaitu sebanyak 18 orang $(25.7 \%)$.

\begin{abstract}
Analisis Bivariat
Analisis bivariat dilakukan untuk mengidentifikasi hubungan variabel independen (sikap kerja) dengan variabel dependen (keluhan nyeri punggung bawah) pada penenun di Kabupaten Batubara.
\end{abstract}

Tabel 4. Hubungan Sikap Kerja dengan Keluhan Nyeri Punggung Bawah

\begin{tabular}{|c|c|c|c|c|c|c|c|c|c|c|}
\hline \multirow{3}{*}{$\begin{array}{l}\text { Keluhan } \\
\text { Nyeri } \\
\text { Punggung } \\
\text { Bawah }\end{array}$} & \multicolumn{6}{|c|}{ Sikap Kerja } & \multirow{3}{*}{$\begin{array}{c}\rho- \\
\text { Value }\end{array}$} & \multirow{3}{*}{$\begin{array}{l}\text { Odd } \\
\text { Ratio }\end{array}$} & \multicolumn{2}{|c|}{$\begin{array}{l}\text { Confidence } \\
\text { Inerval 95\% }\end{array}$} \\
\hline & \multicolumn{2}{|c|}{ Risiko Sedang } & \multicolumn{2}{|c|}{ Risiko Tinggi } & \multicolumn{2}{|c|}{ Total } & & & Lower & Upper \\
\hline & $\mathrm{N}$ & $\%$ & $\mathrm{~N}$ & $\%$ & $\mathrm{~N}$ & $\%$ & & & & \\
\hline Ringan & 10 & $47.6 \%$ & 11 & $52.4 \%$ & 21 & $30.0 \%$ & & 4.659 & 1.485 & 14.617 \\
\hline Berat & 8 & $16.3 \%$ & 41 & $83.7 \%$ & 49 & $70.0 \%$ & 0.015 & & & \\
\hline Total & 18 & $25.7 \% \%$ & 52 & $74.3 \%$ & 70 & $100.0 \%$ & & & & \\
\hline
\end{tabular}

Sumber: Berdasarkan hasil pengolahan data menggunakan SPSS 22 dengan uji chi square

Berdasarkan tabel diatas didapatkan hasil keluhan ringan didapatkan hasil sebanyak 21 orang $(30 \%)$ dan keluhan berat 49 orang $(70 \%)$ dengan keluhan ringan risiko sedang sebanyak 10 orang $(47.6 \%)$ dan keluhan ringan risiko tinggi sebanyak 11 orang (52.4) dengan keluhan berat risiko sedang sebanyak 8 orang $(16.3 \%)$ dan keluhan berat risiko tinggi sebanyak 41 orang $(83.7 \%)$.

Setelah dilakukan uji statistik chi square, diperoleh hasil dari Fisher's Exact Test dengan nilai $\rho$-value 0,015 sehingga dapat disimpulkan bahwa sikap kerja memiliki hubungan signifikan dengan keluhan nyeri punggung bawah pada penenun di Kabupaten Batubara. Nilai Odds Ratio adalah 4.659 berada antara 1.485-14.617 yang berarti responden yang dengan sikap kerja tinggi berisiko sebesar 4.659 kali mengalami keluhan nyeri punggung bahwa tingkat berat.

\section{PEMBAHASAN}

Berdasarkan hasil penelitian yang dilakukan terhadap sikap kerja penenun di Kabupaten Batubara dengan menggunakan 
metode REBA didapatkan bahwa sikap kerja penenun songket tradisional berada pada kategori sedang dan tinggi. Kategori tersebut didapat dari hasil skor menggunakan metode REBA yang menunjukkan sikap kerja penenun berada pada skor terendah adalah 3 dan tertinggi 8. Hasil dari metode REBA didapatkan bahwa pekerja dengan sikap dalam kategori tinggi sebanyak 52 orang $(74.3 \%)$ dan kategori sedang sebanyak 18 orang $(25.7 \%)$. Pekerja dengan sikap kerja tinggi artinya sikap kerja pekerja tersebut memiliki resiko yang tinggi akan terjadinya keluhan nyeri punggung bawah dan mungkin perlu dilakukan tindakan perbaikan terhadap sikap kerja pada pekerja agar tidak mengalami keluhan kesehatan yang lebih berbahaya lainnya. Sedangkan pekerja dengan sikap kerja sedang ialah pekerja yang memiliki resiko rendah untuk terjadinya keluhan nyeri punggung bawah dan belum diperlukan adanya tindakan untuk memperbaiki sikap kerja agar tidak berlanjut keluhan kesehatan yang lebih berbahaya.

Didalam metode pengukuran REBA sikap kerja dapat dilihat dengan diukur leher, punggung, kaki, lengan bawah, lengan atas, pergelangan, beban, dan postur tubuh. Sehingga dari pengukuran ini diketahui sikap kerja atau postur kerja saat bekerja. Untuk mengetahui sikap kerja keseharian penenun songket tradisional dengan gerakan tubuh atau sikap kerja penenun pada saat bekerja adalah mendorong dan menginjak. Dengan gerangan mendorong alat tenunnya maka sikap kerja penenun cenderung membungkuk. Ukuran tempat duduk yang sejajar dengan alat tenun berpengaruh sehingga dapat mempengaruhi sikap kerja yang tidak nyaman.

Berdasarkan hasil kuesioner menunjukkan bahwa keluhan nyeri punggung bawah yang dialami pekerja penenun di Kabupaten Batubara berada dalam kategori ringan dan berat. Penetapan kategori didapatkan dari perhitungan skor kuesioner terhadap 70 pekerja. Hasil skor pekerja berada pada skor terendah 2 dan skor tertinggi 10 dengan ketentuan skor 1-5 termasuk dalam kategori keluhan ringan dan skor 6-10 termasuk dalam kategori keluhan berat. Berdasarkan perhitungan skor kuesioner didapatkan hasil bahwa pekerja mengalami keluhan berat sebanyak 49 orang $(70 \%)$ dan keluhan ringan sebanyak 21 orang $(30 \%)$.

Pekerja dengan keluhan nyeri punggung bawah kategori berat artinya pekerja tersebut merasakan keluhan nyeri punggung yang tergolong tinggi dan mungkin diperlukan tindakan untuk mengurangi keluhan nyeri punggung bawah di kemudian hari agar keluhan tidak berlanjut sampai mengganggu pekerjaan. Pekerja dengan keluhan nyeri punggung bawah kategori ringan artinya pekerja masih merasakan keluhan nyeri punggung bawah yang rendah dan belum diperlukan adanya tindakan terhadap keluhan nyeri punggung bawah pekerja tersebut.

Keluhan nyeri punggung bawah kategori berat pada pekerja penenun dapat dirasakan seperti nyeri punggung bawah sampai ke tungkak kaki dan leher, merasakan nyeri punggung bawah setelah aktifitas, merasakan linu pada tulang belakang, dan merasakan nyeri punggung bawah pada malam hari dan tidak membaik.

Keluhan nyeri punggung bawah kategori ringan pada pekerja penenun dapat dirasakan apabila pekerja merasakan panas pada punggung bawah saat bekerja, merasakan nyeri punggung bawah saat saat bekerja, merasakan pegal pada punggung bawah saat bekerja, dan merasakan nyeri punggung bawah saat duduk yang lama saat bekerja.

Hasil penelitian mengenai hubungan sikap kerja dengan keluhan nyeri punggung bawah yang diuji menggunakan uji $C h i$ Square dengan melihat hasil fisher's exact test menunjukkan bahwa $(\mathrm{p}=0,015<0,5)$ artinya ada hubungan signifikan antara sikap kerja dengan keluhan nyeri punggung bawah pada penenun di Kabupaten Batubara. 
Menenun merupakan kegiatan proses pemembuatan kain songket dari helaian benang dengan menggunakan alat tenun bukan mesin, dimana kegiatan ini menggunakan alat gedogan dilakukan dengan posisi mendorong dan menginjak. Pekerjaan dilakukan selama 10 jam perhari dengan waktu kerja 07.00-18.00 dan waktu istirahat sebanyak 1 kali yaitu pada pukul 12.00-13.00.

Menenun terutama mendorong dan menginjak alat tenun yang memerlukan kekuatan dan ketahanan fisik yang kuat sehingga pekerja bekerja dalam waktu yang lama. Hal ini juga dapat dilihat dari usia pekerja penenun yang berada pada usia $<40$ tahun sebanyak 38 orang dan usia $>40$ tahun sebanyak 32 orang.

Sikap kerja penenun tradisional merupakan sikap kerja dengan gerakan berulang karena berada pada posisi duduk dalam waktu yang lama. Sikap kerja duduk memerlukan tenaga lebih besar mengingat punggung bawah sebagai tumpuan tubuh bekerja dengan posisi duduk terus menerus sangat mungkin akan terjadi penumpukan darah dan berbagai cairan tubuh pada kaki. Terjadinya nyeri punggung bawah sering disebabkan karena posisi duduk yang salah. Pada posisi duduk yang salah tersebut secara langsung maupun tidak langsung dapat menyebabkan otot-otot pinggang menjadi tegang dan dapat merusak jaringan lunak disekitarnya sehingga apabila hal ini tidak segera mendapatkan perhatian secara serius akan dapat menyebabkan timbulnya sakit pinggang secara permanen.

Pekerja memiliki waktu istirahat 60 menit pada pukul 12.00-13.00 WIB. Pekerja penenun disarankan memanfaatkan waktu istirahat untuk melakukan relaksasi otot yang bertujuan untuk meregangkan otot pada tubuh agar dapat mengurangi keluhan nyeri punggung bawah.
Dengan demikian adanya hubungan sikap kerja dengan keluhan nyeri punggung bawah pada pekerja penenun disebabkan sikap kerja penenun dengan sikap yang berulang dan duduk dengan sikap yang tidak alamiah dan tidak ergonomis. Dalam hal ini terutama sikap duduk yang cenderung membungkuk dan tidak adanya sandaran punggung bawah saat duduk yang lama.

\section{KESIMPULAN}

Berdasarkan data penelitian yang dilakukan pada penenun songket di Kabupaten Batubara di dapatkan hasil uji statistik chi square, diperoleh nilai $\rho$-value 0,015 lebih kecil dari nilai $\alpha$ (alpha) 0,5 sehingga dapat disimpulkan bahwa sikap kerja memiliki hubungan signifikan dengan keluhan nyeri punggung bawah (Low Back Pain) pada penenun.

Hal ini ditemukan yang ditemukan pada penenun yang aktif dan menghabiskan waktu yang panjang dalam bekerja. Adanya hubungan sikap kerja dengan keluhan nyeri punggung bawah pada pekerja penenun disebabkan sikap kerja penenun dengan sikap yang berulang dan duduk dengan sikap yang tidak alamiah dan tidak ergonomis. Begitupun dengan sikap kerja yang tidak baik akan merusak sistem musculoskeletal dan memicu terjadinya nyeri punggung bawah khususnya pada penenun di Kabupaten Batubara.

\section{UCAPAN TERIMAKASIH}

Peneliti mengucapkan terimakasih kepada pihak-pihak yang telah memberi bantuan dalam proses penelitian sehingga artikel dapat terselesaikan tepat waktu. 


\section{DAFTAR PUSTAKA}

Agung. (2017). Hubungan Masa Kerja, Posisi kerjadan Indeks Massa Tubuh dengan Kejadian Low Back Pain Pada Tenaga Kerja Bongkar Muat.

Awaluddin, Syafitri, N. M., Rahim, M. R., Thamrin, Y., Rachmat, M., Ansar, J., et al. (2019). Hubungan Beban Kerja Dan Sikap Kerja Dengan Keluhan Low Back Pain Pada Pekerja Rumah Jahit Akhwat Makassar. JKMM, 2(1).

Damayanti, P. J. (2021). Faktor Yang Berhubungan Dengan Keluhan Low Back Pain Pada Penjahit Sebuah Kajian Literatur Artikel. Surakarta.

Depkes RI. (2015). Profil Kesehatan Indonesia. Jakarta: Departemen Kesehatan RI.

Internasional Labour Organization (ILO). (2018).

Kemenkes RI. (2018).

Minghelli, B. (2017). Low Back Pain in Childhood and Adolescent Phase: Consequences, Prevalence and Risk Factors. Journal of Spine, 6(1), 351.

Noli, F. J., Sumampouw, O. J., \& Ratag, B. T. (2021). Usia, Masa Kerja Dan Keluhan Nyeri Punggung Bawah Pada Buruh Pabrik Tahu. Journal of Public Healthand Community Medicine, 2(1).

Notoatmodjo, S. (2012). Metodologi Penelitian Kesehatan. Jakarta: Rineka Cipta.

Rudiana. (2019). Faktor Yang Mempengaruhi Kejadian Low Back Pain pada Buruh Angkat Angkut PT Makassar Tene. Makassar: Universitas Hasanuddin.

Septiani, H. (2018). Gerakan Back Exercise Untuk Mengurangi Keluhan Nyeri Punggung Bawah Pekerja Penambang Pasir Di Depo Desa Jumoyo Salam Magelang.
Yogyakarta: Politeknik Kesehatan Yogyakarta.

Sulaiman, F., \& Sari, Y.P. (2016). Analisis Postur Kerja Pekerja Proses Pengesahan. Jurnal Teknovasi, 18.

Sugiyono. (2017). Metode Penelitian Kuantitatif, Kualitatif, dan $R \& D$. Bandung: CV Alfabeta.

Sugiyono. (2018). Metode Penelitian Kuantitatif. Bandung: Alfabeta.

Tarwaka. (2015). Ergonomi Industri Dasar Pengetahuan Ergonomi dan Aplikasi di Tempat Kerja. Surakarta: Edisi II. Harapan Press.

Tho, I. L. (2018, September). Kejadian Low Back Pain (Lbp) Pada Petugas Penanganan Prasarana Dan Sarana Umum (Ppsu) Di Wilayah Kerja Kecamatan Pademangan Jakarta Utara. EDU MASDA JOURNAL, 2(2).

World Health Organization. (2018). Musculoskeletal Disorders. WHO: Geneva. 